\title{
COMPARATIVE ANALYSIS OF THE IAPWS-IF97 FORMULATION PERFORMANCE FOR THERMODYNAMIC PROPERTIES OF WATER ON A RANKINE CYCLE
}

\author{
J. G. Fonseca Jr. \\ Kobe University, Kobe, Japan \\ jfonseca@bol.com
}

P. S. Schneider

Universidade Federal do Rio Grande do Sul

Departamento de Engenharia Mecânica

Rua Sarmento Leite 425

90050-170 - Porto Alegre - RS - Brasil pss@mecanica.ufrgs.br

\begin{abstract}
The present paper presents the computational implementation of the industrial formulation of the thermodynamic properties of water at liquid and steam phases, proposed by the International Association for the Properties of Water and Steam, known as IAPWS-IF97. The validity field extends over to temperatures $T$ between $0^{\circ} \mathrm{C}$ and $800^{\circ} \mathrm{C}$, for pressures $p$ up to $100 \mathrm{MPa}$. Temperature $T$, specific volume $v$, specific enthalpy $h$, specific entropy $s$, specific heat at constant pressure $c_{p}$ and constant volume $c_{v}$, besides saturation pressure $p_{s}$, are calculated having a pair of known input values $(p, T)$, $(p, h)$ or $(p, s)$. A comparative analysis between the IAPWS-IF97 routines and others, based on foregoing propositions, from an application on Rankine cycle, is made. IAPWS-IF97 has proved to be more precise, mainly because it accounts for the region of compressed liquid, besides requiring less processing time. The development is carried out as FORTRAN90 subroutines and functions and is available for public use according to a General Public License.
\end{abstract}

Keywords: power generation systems, thermodynamic properties of water,IAPWS-IF97, thermal systems simulation

\section{INTRODUCTION}

Design, sizing, simulation and optimization of thermal systems that employ water as a working fluid or at given stages of their processes, strongly depend on the quality of thermodynamic properties data. Its formulation involves the knowledge of analytical relations and experimental data. The technique used does often consist of obtaining equations for pressure, specific volume, specific heat and temperature concerning the vapor phase, relations of pressure and temperature for the saturation region, and for the density on the liquid phase.

The initial motivation for the development in this work started with the simulation of the Danish cogeneration plant AVV1 [Fonseca Jr, 2003], which was an international challenge launched at the ECOS2003 congress. At the time, there were Paz (2002) routines available, built by curve fittings based on Van Wylen et al (1995) data, which are quite fast, however bringing undesirable nonlinear features into the simulation of thermal systems. The routines by Panosso (2003) developed with the correlations proposed by Irvine and Liley (1984), did not cover the range of supercritical states imposed by the AVV1 plant operation.

For these reasons, a more updated formulation was sought, as recommended for industrial use presented by the "International Association for the Properties of Water and Steam - IAPWS" under the label IAPWS-IF97 [Wagner et al, 2000]. It substitutes the previous 1967 industrial formulation, called IFC-67, that had been basic to the calculations on power plants and other energy engineering applications since the 1960's. Its implementation produced satisfactory results in terms of precision, validity range and computational time in relation to the previously cited routines.

\section{IAPWS97 FORMULATION}

\section{Regions}

This formulation features a validity field for temperatures $T$ from $0^{\circ} \mathrm{C}$ to $800^{\circ} \mathrm{C}$ for pressure $p$ up to $100 \mathrm{MPa}$ and from $800^{\circ} \mathrm{C}$ to $2000^{\circ} \mathrm{C}$ for pressures up to $10 \mathrm{MPa}$. Such domain was divided into 5 regions, according to Figure 1. The properties calculated are specific volume $v\left[\mathrm{~kg} / \mathrm{m}^{3}\right]$, specific enthalpy $h[\mathrm{~J} / \mathrm{kg}]$, specific entropy $s[\mathrm{~J} / \mathrm{kgK}]$, specific heat at constant pressure $c_{p}[\mathrm{~J} / \mathrm{kgK}]$, specific heat at constant volume $c_{v}[\mathrm{~J} / \mathrm{kgK}]$, saturation pressure $p_{s}[\mathrm{~Pa}]$ and sound speed $a[\mathrm{~m} / \mathrm{s}]$. In this paper, the equation up to $800^{\circ} \mathrm{C}$ was implemented. The calculation of $a$ was not considered. 


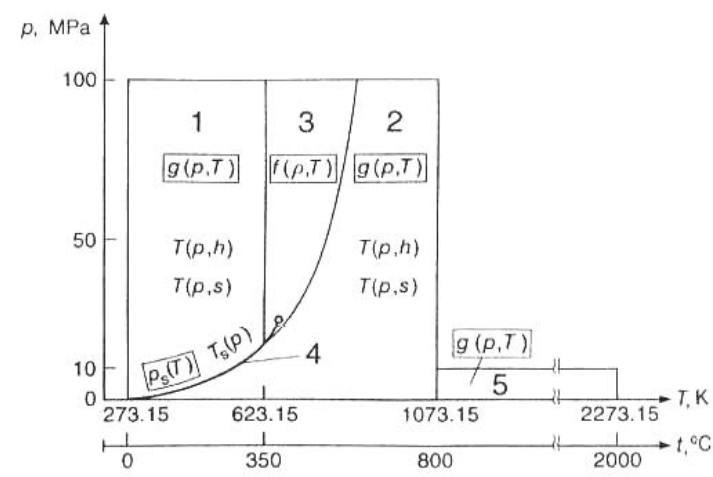

Figure 1. Validity domain of IAPWS-IF97 formulation [Source: Wagner et al, 2000].

Regions 1 and 2 are represented by the fundamental equations for Gibbs' specific free energy $g$ $(p, T)$. Region 3 works according to Helmholtz's fundamental equation for specific free energy $f(\rho, T)$, where $\rho$ is the fluid density. Region 4 corresponds to the saturation curve and is, therefore, expressed in a function of $p_{s}(T)$.

According to Callen (1985) Gibbs and Helmholtz free energies are Legendre's partial transforms of a certain variable, applied to a fundamental equation of the $U(S, V, N 1 \ldots)$ type where $U$ is the internal energy, $S$ the entropy, $V$ the volume and $N 1$ the number of moles.

One of the goals of these transforms is to enable the representation of intensive parameters as independent variables in the equations of state, and thus calculate non-measurable parameters from measurable ones, such as pressure and temperature. The Gibbs' free energy is a Legendre's transform who simultaneously replaces entropy by temperature and volume by pressure as independent variables. The Helmholtz's free energy is the Legendre's partial transform applied to a $U(S, V, N I, \ldots)$ equation which substitutes entropy for temperature as an independent variable.

This set of basic equations allows for the obtaining of all the properties through their derivatives, leaving aside long lasting iteration processes. Furthermore, the formulation puts forth recurrence equations for working with other entry pairs, different from the $(p, T)$ pair, such as the $T(p, s)$ and the $T(p, h)$ functions, and the saturation temperature $T_{s}(p)$ for the saturation curve. These recurrence equations aim at avoiding the iteration process whenever working with other pairs, thus gaining computational value. For instance, to calculate $h(p, s), T(p, s)$ is first calculated, and then $h(p, T)$.

Nevertheless, the use of this concept calls for extremely good numeric consistence between equations. Therefore, the formulation presents the following consistence values:

a) The temperature determined by the recurrence equation $T(p, h)$ has to agree with the calculated temperature for the same $p$ and $h$ of the basic correspondent equation $g(p, T)$ for a tolerance of $\Delta T_{t o l}$. Such tolerance varies around $\pm 25 \mathrm{mK}$ for the entire region 1 and entropy values lower than $5.85 \mathrm{~kJ} / \mathrm{kgK}$ for region 2. The tolerance decreases to $\pm 10 \mathrm{mK}$ for entropies higher than $5.85 \mathrm{~kJ} / \mathrm{kgK}$ in region 2. Such lower tolerance is particularly important for the energy industry.

b) The temperature determined by the recurrence equation $T(p, s)$ has the same tolerances described in item a.

c) The saturation pressure calculated by the $T_{s}(p)$ equation has a bias on $\Delta p_{s}$ less than $\pm 0.003 \%$ of the $p_{s}$ determined by the $p_{s}(T)$ equation.

Such inconsistencies were determined by the group that has developed the formulation after tests in calculations of characteristic power cycles, in order not to cause numeric problems whenever the use of basic and recurrence equations was applied alternately. Still, it is worth highlighting that these allowed numerical inconsistencies between basic and recurrence equations are extremely small, equaling about 0.1 of the uncertainty of the values found in the IAPWS-95 scientific guideline, upon which the formulation is based.

\section{Precision}

Concerning precision, the values of the properties $v$, $h$ and $p$ generally correspond to the values of the formulation for the scientific use of the IAPWS-95, with tolerances found in the 1994 version of the "International Skeleton TablesIST-85" tables (Wagner et al, 2000): between $\pm 0.01 \%$ and $0.3 \%$ for $v$, between $0.1 \%$ and $0.3 \%$ for $h$ and of $0.025 \%$ for $p_{s}$. For $p$ values lower than $1 \mathrm{MPa}$ and for the saturation region with $T$ lower than $100^{\circ} \mathrm{C}$, formulation tolerances are different from those proposed by the IST-85 regarding the technical requirements for $h$ and $v$. The values in this region are $\pm 0.01 \%$ for $v, \pm 0.1 \%$ for $h$. As for $c_{p}$, the values show a variation of $\pm 1 \%$ in relation to the IAPWS-95 except for the region close to the critical point where larger biases are allowed. According to the precision parameters described above, the agreement between the industrial formulations is ensured.

\section{Maximal inconsistence between region borders}

Regarding the continuity of the frontiers between regions, the formulation takes up defined values as in the "Minutes of the Meeting of the International Formulation Committee of ICPS" [Wagner, op sit.]. These values, established for the IFC-67, leave room for the permissible differences in the responses of the properties along the borders between regions, whenever these are calculated for all the equations valid for the correspondent border. The continuity requirements assumed by the IAPWS-IF97 are presented in the table below:

Table 1. Continuity Requirements assumed by the IAPWSIF97 for maximal inconsistence between region borders [Source: Wagner et al, 2000]

Steam phase

\begin{tabular}{lll} 
Specific volume & $\Delta v$ & $\pm 0.05 \%$ \\
Specific enthalpy & $\Delta h$ & $\pm 0.2 \mathrm{~kJ} / \mathrm{kg}$ \\
Specific heat at constant $\mathrm{p}$ & $\Delta c_{p}$ & $\pm 1 \%$ \\
Gibbs' specific free energy & $\Delta g$ & $\pm 0.2 \mathrm{~kJ} / \mathrm{kg}$ \\
\hline
\end{tabular}


CIÊNCIA/SCIENCE

Saturation

\begin{tabular}{lll} 
Pressure & $\Delta p_{s}$ & $\pm 0.05 \%$ \\
Temperature & $\Delta T_{s}$ & $\pm 0.02 \%$ \\
Gibbs' specific free energy & $\Delta g$ & $\pm 0.2 \mathrm{~kJ} / \mathrm{kg}$ \\
\hline
\end{tabular}

\section{IMPLEMENTATION}

The code developed in the present work automatically establishes which equations shall be used according to the selection done in the "Pair" entry data, that appears in the first block of the diagram in Figure 2.

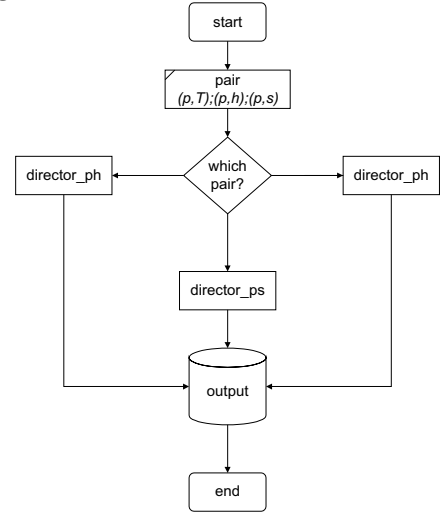

Figure 2. Schematic diagram of the main program.

The three possible choices are a combination of pressure $p$ with the temperature $T$, specific enthalpy $h$ or specific entropy $s$, forming the pairs $(p, T),(p, h)$ or $(p, s)$, which allows for calculating $v, u, s, h, c_{p}$ and $c_{v}$. In the Director $p t$ subroutine validity tests are carried out, as well as tests that enframe the point in one of the three regions covered by the formulation. The subroutines Director $\_s$ and Diretor $p h$ work in different ways, since they use recurrence equations.

\section{COMPARATIVE ANALYSIS}

The results obtained using the IAPWS97 routines were compared with the Irvine and Liley (1984) equations, as implemented by Panosso (2003). The latter formulation has preceded the IAPWS97 but likewise, based on thermodynamic and experimental data. Both were applied on a Rankine cycle with one reheating and three regenerations (figure 3), plus auxiliary equipments.

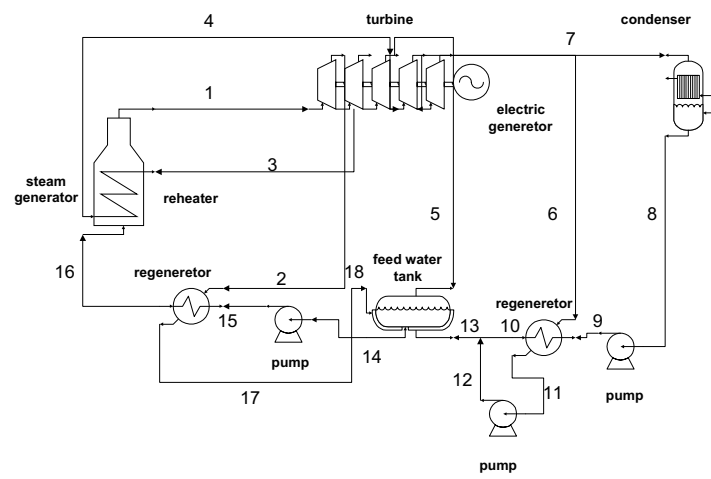

Figure 3. Rankine cycle diagram with reheating and regenerators
Input data prescribed for the solution of the problem are shown in Table 2, and the percentage differences of the more relevant results of the simulations are shown in Table 3.

Table 2. Data prescribed for the Rankine cycle with reheating and regeneration [Source: Panosso, 2003]

\begin{tabular}{lc}
\hline Datum & Value \\
\hline Turbine total power $[\mathrm{MW}]$ & 63.0 \\
Pressure at state $1[\mathrm{MPa}]$ & 11.3 \\
Temperature at state $1\left[{ }^{\circ} \mathrm{C}\right]$ & 530 \\
Pressure at state $2[\mathrm{MPa}]$ & 2.3 \\
Pressure at state $3[\mathrm{MPa}]$ & 2.2 \\
Pressure at state $4[\mathrm{MPa}]$ & 2.2 \\
Temperature at state $4\left[{ }^{\circ} \mathrm{C}\right]$ & 530.0 \\
Pressure at state $5[\mathrm{MPa}]$ & 0.9 \\
Pressure at state $6[\mathrm{MPa}]$ & 0.09 \\
Pressure at state $7[\mathrm{MPa}]$ & 0.007 \\
Quality at state 18 & 0.2 \\
Isoenthropic turbine efficiency & 0.8 \\
Isoenthropic pump efficiency & 0.7 \\
Stem generator efficiency & 0.8 \\
Subcooling degree at condenser out- & 5.0 \\
put $\left[{ }^{\circ} \mathrm{C}\right]$ & \\
Subcooling degree at regenerator hot & 0 \\
output $\left[{ }^{\circ} \mathrm{C}\right]$ & \\
Final temperature difference * $\left[{ }^{\circ} \mathrm{C}\right]$ & 4.0 \\
Specific volume $\left[\mathrm{m}{ }^{3} / \mathrm{kg}\right]$ & 0.001001 \\
Quality at regenerator cold output & 0 \\
\hline$*$ Difference in temperature, in a regenerator, between the fluid saturation \\
temperature that is extracted from the turbine and is entered into the regen- \\
erator and the temperature of the fluid of the main current that leaves the \\
regenerator.
\end{tabular}

Table 3. Relative bias between the results of the Rankine Cycle simulation and the reheating and regeneration tests, using 2 different programs.

\begin{tabular}{lc}
\hline Datum & $\begin{array}{c}\text { Panosso x present } \\
\text { work* }(\%)\end{array}$ \\
\hline $\begin{array}{l}\text { Enthalpy at state } 13[\mathrm{~kJ} / \mathrm{kg}] \\
\text { Total power required on pumps }\end{array}$ & 0.2 \\
[MW] & 2.41 \\
Required heat input on the & 1.71 \\
steam generator [MW] & 2.41 \\
Mass flow [kg] & $\mathbf{1 . 7 8}$ \\
Cycle Efficiency & \\
\hline
\end{tabular}

*[(Panosso - present work) / Panosso] x 100 (\%)

The percentage differences have remarkably increased for some response variables as they are important to cycle analysis such as global efficiency, steam generator power, mass flow, among others. One of the factors to generate this increase was some cascade error brought about by the higher number of components in the cycle, besides the error introduced by the enthalpy calculation at the output of the pump at the equation formulation. The Panosso formulation is not valid for the region of compressed liquid, which is alternatively calculated by the saturated liquid approximation, state 13 in the table, as obtained from iterations.

The power calculation at the pumps showed an important percentage difference as regardful of the bias found in mass flows, determined by pressure differences. Such bias 
resulted in an increase in percentage difference in all other values depending on it, including the efficiency of the cycle.

Another interesting fact is that the use of the IAPWS-IF97 formulation has reduced significantly the simulation time from $65 \mathrm{~s}$ to less than $10^{2} \mathrm{~s}$, as measured on a Pentium $166 \mathrm{MHz}$ computer with 2 MB RAM.

\section{CONCLUSIONS}

The routine for the calculation of the thermodynamic properties of water has presented good performance in relation to precision and processing time. Its ability to calculate the properties of water in the compressed liquid region has proved to be important, since the cycle overall thermal efficiency has reached up to $1.78 \%$ different. This discrepancy may strongly impact the decisions concerning undertaking power generation projects. The routines proposed in this work may be employed independently, or coupled to thermal system simulation programs, in which water is the working fluid, or is part of the studied processes. Its validity range includes supercritical pressures, which allows for treating modern problems of thermal power plants, for instance. For those cases in which properties regions are previously known, it is possible to extract specific subroutines to the proposed set, making the computational time even faster and preventing problems inherent to interactive calculations.

\section{NOMENCLATURE}

a - sound speed $[\mathrm{m} / \mathrm{s}]$

$c_{p}$ - specific heat at constant pressure $[\mathrm{J} /(\mathrm{kg} \mathrm{K})]$

$\mathrm{c}_{\mathrm{v}}$ - specific heat at constant volume $[\mathrm{J} /(\mathrm{kg} \mathrm{K})]$

$f(\rho, T)$ - Helmholtz's specific free energy

$\mathrm{g}(\mathrm{p}, \mathrm{T})$ - Gibbs' specific free

$\mathrm{h}$ - specific enthalpy $[\mathrm{J} / \mathrm{kg}]$

$\mathrm{N} 1$ - number of moles.

$\mathrm{p}$ - pressure $[\mathrm{Pa}]$

$\mathrm{p}_{\mathrm{s}}$ - saturation pressure $[\mathrm{Pa}]$

$\mathrm{S}$ - entropy $[\mathrm{J} / \mathrm{K}]$

$\mathrm{s}$ - specific entropy $[\mathrm{J} /(\mathrm{kg} \mathrm{K})]$

$\mathrm{T}$ - temperature $[\mathrm{K}]$

$\mathrm{U}$ - internal energy $[\mathrm{J}]$

$\mathrm{V}$ - volume $\left[\mathrm{m}^{3}\right]$

$\mathrm{v}$ - specific volume $\left[\mathrm{kg} / \mathrm{m}^{3}\right]$

$\rho$ - fluid density.

\section{REFERENCES}

Callen, H. B., 1985, Thermodynamics and Introduction to Thermostatics, $2^{\circ}$ ed., New York, John Willey \& Sons.

Fonseca Jr, J.G., 2003, “Análise Energética e Exergética de um Ciclo Rankine com Aquecimento Distrital: Estudo de uma Planta Termelétrica", Master Thesis, Programa de PósGraduação em Engenharia Mecânica, Universidade Federal do Rio Grande do Sul, Porto Alegre.

Irvine, T.F. and Liley, P., 1984, Steam and Gas Tables with Computer Equations, Academic Press, Florida.

Panosso, G.C., 2003, "Métodos de Simulação para Ciclos de Rankine", Master Thesis, Programa de Pós-Graduação em Engenharia Mecânica, Universidade Federal do Rio Grande do Sul, Porto Alegre.

Paz, A. E. C., 2002, "Simulação de Sistemas Térmicos de Potência para Geração de Energia Elétrica", Master Thesis, Programa de Pós-Graduação em Engenharia Mecânica, Universidade Federal do Rio Grande do Sul, Porto Alegre.

Sandler, S. I., 1999, Chemical and Engineering Thermodynamics, John Wiley \& Sons, $3^{\text {a }}$. Ed., New York.

Stoecker, W. F., 1989, Design of Thermal Systems, McGraw-Hill, New York

Van Wylen, G., Sonntag, R, e Borgnakke, C, Fundamentos da Termodinâmica Clássica, Editora Edgard Blücher Ltda., São Paulo, 1995

Wagner, W., Cooper, J. R., Dittmann, A., Kijima, J., Kretzschmar, H. J., Kruse, A., Mares, R., Ogushi, K., Sato, H., Stöcker, I., Sifner, O., Takaishi, Y., Trübenbach, J., Willkommen, Th., 2000, "IAPWS Industrial Formulation 1997 for the Thermodynamic Properties of Water and Steam", Journal of Engineering for Gas Turbines and Power - ASME, Vol 122, pp 150 - 182.

NOTE- Routines on FORTRAN90/95 may be used as an independent program or coupled to a system simulating program, in the form of subroutines or functions. They are available on the site of the Federal University of Rio Grande do Sul:

www.geste.mecanica.ufrgs.br/eng03025/index.htm as General Public License (GPL), together with descriptive documents of implementation. 